\title{
A FORMAÇÃO LÚDICA DO EDUCADOR E A QUESTÃO DA DIVERSIDADE ÉTNICA NO ESPAÇO ESCOLAR INFANTIL
}

\section{EDUCATOR 'S PLAYFUL AND THE QUESTION OF ETHNIC DIVERSITY IN CHILDREN'S SCHOOL SPACE}

\section{LA FORMACIÓN LÚDICA DEL EDUCADOR Y LA CUESTIÓN DE LA DIVERSIDAD ÉTNICA EN EL ESPACIO ESCOLAR INFANTIL}

\author{
Suselaine Aparecida Zaniolo Mascioli \\ Pós-Doutora em Educação - sub-área: Educação Infantil - UFSCAr. Pesquisadora Integrante \\ do "Núcleo de Estudos e Pesquisas sobre a Escola de Vigostky" - Neevy - UFSCar e do \\ GEERERI Grupo de Estudos “Educação e Relações Étnico-Raciais na Temática Indígena”. \\ Docente: FIJ- Faculdades Integradas de Jáu; UNIP -Universidade Paulista. \\ E-mail: susezan@bol.com.br
}

\section{RESUMO}

Este trabalho tem por objetivo problematizar a formação lúdica do educador e a relevância dos jogos, brinquedos e brincadeiras como estratégia pedagógica para se abordar a diversidade étnica no ambiente escolar infantil. Garantir o tempo e o espaço dos jogos, brinquedos e brincadeiras na vida da criança é responsabilidade não só das famílias, mas também das instituições escolares. A escola ao contribuir para o resgate da ludicidade infantil deve permitir um trabalho educacional que explore o aprendizado das peculiaridades presentes nas diferentes culturas.

Palavras-chave: Formação lúdica. Diversidade Étnica. Educador.

\begin{abstract}
This paper aims to problematize the educator 's playful education and the relevance of games, toys and games as a pedagogical strategy to address ethnic diversity in the children' s school environment. Ensure the time and space of games, toys and games in the children's lives is not only the responsibility of families, but also educational institutions. The school to contribute to the rescue of childhood playfulness should allow educational work that explores learning the quirks present in different cultures.
\end{abstract}

Keywords: Educator 's playful. Ethnic Diversity. Educator.

\section{RESUMEN}

Este trabajo tiene por objetivo problematizar la formación lúdica del educador y la relevancia de los juegos, juguetes y juegos como estrategia pedagógica para abordar la diversidad étnica en el ambiente escolar infantil. Garantizar el tiempo y el espacio de los juegos, juguetes y juegos en la vida del niño es responsabilidad no sólo de las familias, sino también de las instituciones escolares. La escuela al contribuir al rescate de la ludicidad infantil debe permitir un trabajo educativo que explore el aprendizaje de las peculiaridades presentes en las diferentes culturas.

Palabras clave: Formación lúdica. Diversidad Étnica. Educador. 


\section{INTRODUÇÃO}

Desde o início de minha trajetória acadêmica e profissional, tenho participado de encontros com educadores, ministrando vivências, em forma de "oficinas" e cursos, junto a professores e futuros professores, acreditando que "o adulto é capaz de recuperar o lúdico em sua vida, recuperando assim a própria infância e despertando a criança eterna que se encontra dentro dele" (MASCIOLI, 2006, p. 114).

Durante minha atuação profissional - tanto nos momentos de ação direta com crianças como nos momentos de ação junto aos educadores em formação ou com educadores em exercício sempre tive, em minhas reflexões, a preocupação central de respeitar e estimular as características e linguagens que julgava serem próprias da infância. Contudo, desde então, venho constatando que "parte da sociedade ainda considera o brincar uma atividade fútil, que não é, muitas vezes, valorizada pelos próprios adultos envolvidos na educação." (MASCIOLI, 2012, p.117-118).

Possibilitar aos adultos - sobretudo professores e professores em formação - o conhecimento teórico e empírico sobre o brincar, parece-me imperativo.

Defendo, assim, o que nomeio de 'Formação Lúdica do Educador' e a necessidade de se oferecer espaços escolares e cursos de formação de educadores que propiciem ao educando situações de aprendizado variadas e desafiadoras, que estimulem seu processo de desenvolvimento intelectual e criador, assim como o acesso ao saber elaborado, científico, sem deixar de lado a alegria de aprender e de estar no ambiente escolar.

Às minhas preocupações com a infância e com a formação lúdica do educador, foram reunidas reflexões advindas do universo que permeia a questão da diversidade étnica no espaço escolar infantil e o papel do educador que anseie desempenhar uma ação pedagógica lúdica e centrada no respeito às diferenças.

A diversidade étnica é um tema que se apresenta nos currículos e nas políticas para a educação e para a infância. Manifesta-se nas brincadeiras e demais formas de manifestação das culturas infantis e deve assim estar presente nas práticas educativas das instituições de Educação Infantil.

Assim sendo, o presente artigo tem por objetivo problematizar a formação lúdica do educador e a relevância dos jogos, brinquedos e brincadeiras como estratégia pedagógica para se abordar a diversidade étnica no ambiente escolar infantil.

Aponto, portanto, para a necessidade de que as escolas eduquem os indivíduos desde a mais tenra idade para que possam reconhecer, compreender e reverenciar as diferenças 
presentes nas distintas culturas e, para tanto, respeitem primeiramente a linguagem própria da infância: a ludicidade.

\section{A formação lúdica do educador}

O professor, deveria sempre representar a figura de um sujeito capacitado para intervir e provocar o desenvolvimento máximo da capacidade de seus alunos, favorecendo-lhes novas e mais complexas aprendizagens.

Assim sendo, torna-se essencial que sejam disponibilizadas ao professorado em formação e/ou em serviço, oportunidades em que o educador seja o sujeito de seu próprio processo de construção e apropriação de conhecimentos, exercitando e estimulando suas habilidades, aprendendo por meio de suas próprias percepções e atitudes; reflexões individualizadas e coletivizadas com outros profissionais.

Porém, na realidade de grande parcela dos educadores responsáveis pelo ensino das escolas públicas, observa-se que nem sempre os educadores recebem formação específica para lidar com o imenso universo do brincar, dos jogos, brinquedos e brincadeiras, ou seja, uma formação lúdica.

Por formação lúdica, compreendo tanto à apropriação de conhecimentos teóricos por meio de leituras de textos que evidenciem conceitos, condutas e definições, como também a aquisição de conhecimentos empíricos - pautados na experimentação e ampliação de seus repertórios lúdicos. "Não se almeja aqui, elaborar uma apologia ao pragmatismo, mas, sim abalizar a necessidade que se impõe ao professor que pretende fazer uso das brincadeiras em sua prática educativa." (MASCIOLI, 2009, p.127).

Para o bom aproveitamento das situações lúdicas, o adulto precisa ser educado, assim como a criança. Trata-se, portanto, de uma formação especifica sustentada, assim como deveria ser toda ação educativa, por consistentes "mediações pedagógicas".

A mediação pedagógica pauta-se em ações intencionais e sistemáticas, em orientações deliberadas e explícitas. Diferencia-se da mediação cotidiana que decorre de vivências sociais cotidianas, em contextos de situações imediatas e circunstanciais.

\section{$O$ resgate da cultura infantil}

A cultura infantil é um dos temas marginalizados pelas propostas curriculares. Os modos próprios da infância de ver a sociedade, suas interpretações, vivências, predileções, jogos, brinquedos e brincadeiras. Muito se estuda a importância do brincar para o desenvolvimento infantil, porém, pouco se reflete e analisa os significados culturais, 
históricos e peculiares dos jogos, brinquedos e brincadeiras. (SANTOMÉ, 2009; BUJES, 2002).

A tentativa de valorização dos jogos, brinquedos e brincadeiras no processo educativo é uma maneira de tentar compreender a multiplicidade cultural do universo lúdico infantil e respeitar cada vez mais a criança como criança. "Os espaços escolares abarcam crianças com vivências e repertórios lúdicos distintos e que devem ser respeitados e ampliados." (MASCIOLI, 2006, p. 108).

Independentemente de classe social, todas as crianças sentem a necessidade de brincar e desenvolver atividades gostosas, prazerosas. Assim, é fundamental que se assegure à criança uma vivência intensa do caráter lúdico "capaz de formar a base sólida para a participação cultural e, sobretudo para o exercício do prazer de viver.” (MARCELLINO, 2000, p. 38).

$\mathrm{O}$ direito de brincar, se apresenta como um dos direitos da cidadania, da mesma forma que o direito à cultura, à arte, ao esporte e ao lazer. Sabe-se, porém, que muitas crianças encontram-se desprovidas desse direito e privadas da própria infância.

Parece-nos indiscutível que a brincadeira é uma linguagem universal. Não importa em que país do mundo, não importa se os brinquedos são improvisados a partir do quotidiano da criança ou se são reproduções luxuosas e caras do mundo dos adultos. Em qualquer lado, em qualquer época, há crianças que brincam. Por isso, a origem do brinquedo perde-se nas profundezas do tempo. Poder-se-á dizer que o primeiro brinquedo nasceu com a primeira criança, quaisquer que tenham sido a latitude e a longitude em que essa criança nasceu. (SARAIVA, 2002, p. 2. Grifo nosso).

É sabido que nem todas as crianças têm as mesmas experiências lúdicas na infância, tampouco as infâncias são configuradas igualmente, mas é possível acreditar que "onde quer que exista uma criança existe um brinquedo, muitas vezes, até, criado pela sua imaginação. Brincar e jogar sempre fizeram parte da vida da criança, ajudando-a a descobrir o que a rodeia, o mundo dos adultos, a construir a sua personalidade, a aprender a viver." (SARAIVA, 2002, p.2).

Carneiro (2012) aponta que apesar de termos numerosos e recentes estudos que defendem a importância do brincar enquanto um bem vital e cultural, "a sua prática nunca esteve tão ameaçada" (CARNEIRO, 2012, p. 89).

Para a referida autora os obstáculos em relação à utilização da brincadeira são de origens diversas e, entre eles estão à falta de clareza conceitual, as políticas públicas, as organizações curriculares, a desvalorização da atividade e o despreparo dos profissionais da educação infantil. 
Outro obstáculo com que o universo do brincar se depara diz respeito aos lugares e espaços, pois, “[...] não só é preciso assegurar o direito à brincadeira, como é também necessário fomentar a criação de novos lugares para brincar, bem como de uma consciência lúdica que garanta um justo lugar à brincadeira na vida.” (FORTUNA, 2004, p. 3).

Marcellino (2000) afirma que as atividades lúdicas são subtraídas do cotidiano infantil, cada vez mais precocemente e, que, o período referente à infância, já não é mais um espaço predominantemente lúdico.

Segundo o autor, o adulto quando busca preparar a criança para o futuro, preenche todo o tempo da mesma com atividades, afazeres e compromissos, obrigando-a a renunciar o momento presente. O tempo e o espaço para o lúdico se tornam neste sentido, cada vez mais restritos na vida infantil, pois o momento destinado para a brincadeira acaba se diluindo diante da hora da tarefa, hora da escola, hora do inglês, hora da computação etc. "Ora, o mundo do brinquedo, em essência, não se prende à preparação sistemática para o futuro, mas à vivencia do presente, do agora.” (MARCELLINO, 2000, p. 37).

O movimento de furto do lúdico no período da infância se apresenta hoje em todas as camadas sociais.

\begin{abstract}
Nas camadas de menor poder aquisitivo um número considerável de crianças tem, desde cedo, obrigações familiares e até mesmo profissionais, devido às necessidades financeiras da família, complementando, ou mesmo mantendo o orçamento doméstico [...] em outras camadas há também inúmeros casos de crianças que, apesar de não serem premidas pelas necessidades econômicas, têm, desde muito cedo, uma série de obrigações, frutos de "investimentos" feitos pelos pais, para que, no futuro, sejam os adultos requeridos pelo padrão de sua classe social. (MARCELLINO, 2000, p. 37).
\end{abstract}

Sarmento (2003) esclarece que é através do brinquedo que a criança irá reproduzir o universo adulto e, assim, produzir o universo infantil. O imaginário da criança é o modo pelo qual ela estabelece sua relação com o mundo, construindo através do brincar a dimensão simbólica da cultura infantil. "Contrariamente aos adultos, entre brincar e fazer coisa séria não há distinção, sendo o brincar muito do que as crianças fazem de mais sério.” (SARMENTO, 2003, p. 15-16).

Assim, a criança brinca para conhecer a si própria e aos outros em suas relações; para expressar emoções; para conhecer os objetos em seu contexto e o uso cultural dos objetos; para realizar coisas que talvez sejam impossíveis em seu convívio e sua realidade; e, entre outras coisas, para aprender as normas do mundo em que vive, os comportamentos e os hábitos determinados pela sua própria cultura. A criança, portanto, "é um agente transmissor 
de cultura, na medida em que leva os seus jogos e brinquedos para onde quer que vá. Em suas mãos tudo se transforma em brinquedo: um pedaço de papel, de cordel, uma flor, uma pedra, o próprio corpo humano. (SARAIVA, 2002, p.2).

O brincar é, neste processo lúdico, um caminho viável para que ela possa também reconhecer as diversidades culturais.

Ao brincar as crianças trazem para suas brincadeiras o que veem, escutam, observam e experimentam. Revelam suas visões de mundo, suas descobertas. As brincadeiras ficam mais interessantes quando associadas às diferentes linguagens, entre ela a corporal. $\mathrm{O}$ corpo comunica e é preciso aprender a ler suas mensagens.

Brougère $(2004 ; 2003 ; 2001 ; 1994)$ denomina esse fazer infantil com o brinquedo de cultura lúdica. $\mathrm{O}$ autor aponta também que garantir o tempo e o espaço dos jogos, brinquedos e brincadeiras na vida da criança é responsabilidade não só das famílias, mas também das instituições escolares.

Acredita-se ainda, que a escola, desde o nível da Educação Infantil, ao contribuir para o resgate do lúdico na infância deve permitir um trabalho educacional que explore o aprendizado das peculiaridades presentes nas diferentes culturas e por consequência, nas diferentes culturas lúdicas. Mas qual o lugar que a diferença e a diversidade ocupam no espaço da Educação infantil?

\section{A diversidade étnica no espaço escolar Infantil}

A realidade cultural brasileira é estabelecida em meio à diversidade. No Brasil “convivemos com portugueses, indígenas, de diversas etnias, negros, libaneses, eslavos, italianos, alemães, japoneses, e seus descendentes e cultivamos certo prazer neste convívio.” (FRANÇA, 2010, p.44).

Aparentemente, muitas escolas na atualidade, revelam em suas propostas pedagógicas e orientações curriculares, um ideário discursivo que procura atender às novas concepções sobre a diversidade presente nessa sociedade multicultural e pluriétnica.

Porém, a noção de identidade nacional amplamente definida pela transmissão da cultura tradicional, tem sido historicamente a cultura de exclusão, ignorando as múltiplas narrativas, histórias e vozes de grupos culturais politicamente subordinados.

A Educação poderia ser o mais eficiente caminho para estimular a consciência cultural do indivíduo, começando pelo reconhecimento e apreciação da cultura local. Contudo, a educação formal no Terceiro Mundo Ocidental foi completamente dominada pelos códigos culturais europeus e, 
mais recentemente, pelo código cultural norte-americano branco. (BARBOSA, 2010, p. 1).

Santomé (2009) explicita que nas escolas brasileiras os conteúdos tradicionais das culturas hegemônicas são tomados como o centro do ensino, enquanto as culturas das minorias são silenciadas ou relegadas aos "temas transversais" 1 ".

Muito se tem discutido sobre a Lei 11.645/08 e as dificuldades e desafios da sua implementação na rede básica de ensino (público e privado). Complementando a lei 10.639/03, que obriga o ensino da História e Cultura Africana e Afro-brasileira, a lei 11.645/08, acrescenta a obrigatoriedade do ensino da História e Cultura Indígena.

Apesar de a lei 11.645 não fazer menção direta ao nível da Educação Infantil, ele é legalmente reconhecido como a primeira etapa da Educação Básica e, como tal, é nele que se iniciam as abordagens sobre a temática. "As tensões raciais estão chegando às escolas brasileiras. Em boa hora. Se não há como ocultá-las e silenciá-las na sociedade, não haverá como teimar em ocultá-las e silenciá-las no sistema escolar como um todo, da educação infantil à superior”. (ARROYO, 2007, p. 110).

Para o autor, é preciso:

[...] avançar mais na criação de normas compulsórias sobre a eliminação de todo preconceito racial no material escolar e nas condutas dos alunos e profissionais das escolas. Desenvolver políticas mais coerentes de produção de novos materiais. Incorporar representantes do movimento negro, pesquisadores, intelectuais e educadores na formulação dessas políticas. Políticas mais focadas de formação inicial de professores a administradores para o trato da diversidade e da pedagogia multirracial. Obrigar os centros de formação a incorporar nos currículos de pedagogia e licenciatura o conhecimento da nossa realidade multirracial. (ARROYO, 2007, p.114).

Tomando a cultura indígena como mote em nossa análise, percebemos que apesar dos avanços legais, sobretudo os relacionados à implementação da Lei 11.645/08, ainda na maioria dos casos "a cultura indígena só é tolerada na escola sob a forma de folclore, de curiosidade e esoterismo; sempre como uma cultura de segunda categoria." (BARBOSA, 2010, p. 1).

Entende-se, assim como Nunes (2006), que analisar o cenário presente nas realidades escolares brasileiras é um exercício que exige um olhar para o passado e para a "teia de interesses e processos, econômicos e políticos que, em última instância, determinam ou

\footnotetext{
${ }^{1}$ Os temas transversais são constituídos pelos Parâmetros Curriculares Nacionais (PCN's) e compreendem seis áreas: Ética, Orientação Sexual, Meio Ambiente, Saúde, Pluralidade Cultural e Trabalho e Consumo. Apresentam conteúdos que não fazem parte obrigatória do currículo escolar, mas que podem e devem ser explorados em sala de aula. Expressam conceitos e valores básicos à democracia e à cidadania e obedecem a questões importantes e urgentes para a sociedade contemporânea .
} 
condicionam a identidade da escola e de sua significação ou finalidade social." (NUNES, 2006, p. 12).

Exige também, que se busque definir o que se compreende por educação e por escola.

Nunes (2006) aponta que a definição de educação pode ser delineada em um sentido lato, mas também em um sentido restrito. No primeiro caso, apresenta-se uma acepção genérica, que situa a educação como algo intrínseco à condição e constituição humana e a ação civilizatória do homem, portanto, "educar seria hominizar-se, transformar-se em homem, produzir-se como homem, diferenciando-se da natureza biológica e do mundo instintivo, considerado mundo selvagem, que é o estado natural.” (NUNES, 2006, p. 12).

Essa compreensão mais ampla de educação é, segundo o autor, conhecida como endoculturação:

Endoculturar significa trazer para dentro da cultura, integrar ou introduzir, no grupo humano, as novas gerações, os novos participantes do processo humano. As formas técnicas, os instrumentais simbólicos e materiais, representativos e reais, que produziram a inserção de cada ser humano no universo simbólico e cultural, da tradição da cultura, da realidade econômico-formal e cultural ou ideológica seria o substrato do fenômeno cultural. A educação, portanto, no sentido lato [...] coincidiria com a própria trajetória de produção da condição humana. (NUNES, 2006, p. 13).

Lembra-se, contudo que ter acesso à cultura parece uma coisa simples, mas não é. Ela precisa ser vivenciada, as pessoas terão que "vivê-la, que tecê-la, construí-la em si mesmas, com muitas lágrimas, renúncias marcas no corpo e na alma, alegrias, e realizações." (PASSOS, 2010, p. 23).

O sentido restrito de educação ao qual Nunes (2006) se refere, vincula-se ao processo de escolarização, da criação da escola enquanto instituição formalizada, estruturada e sistematizada pela sociedade, com a finalidade de manter a interrelação entre as gerações e repassar assim não só um arcabouço cultural, como também os códigos comportamentais e morais [...] entende-se por essa determinação a intrínseca responsabilidade de um grupo social criar, conservar, transmitir e repassar, através de suas instituições educacionais, seu núcleo cultural e seus determinantes institucionais de sustentação. (NUNES, 2006, p. 14).

Faria Filho e Gonçalves (2005) constatam que diversas pesquisas reconhecem que os processos educativos integram processos culturais mais amplos e que a cultura existente no interior de uma escola "ainda que possa ser considerada em particular, pela especificidade das variadas práticas dos sujeitos que ocupam esse espaço, articula-se com práticas mais amplas da sociedade.” (FARIA FILHO e GONÇALVES, 2005p. 32). 
Diante desse arcabouço de ideias e constatações precisamos refletir: a quem e a quais objetivos a educação tem servido? Quem estamos formando e com quais valores éticos? Que materiais pedagógicos - entre eles brinquedos, jogos, livros infantis, vídeos etc. - estamos disponibilizando para as crianças e qual a influência dos mesmos no processo de autoidentificação das crianças?

Essas e outras reflexões parecem permear os desafios colocados à escola, ao educador e aos processos educativos, principalmente ao se almejar um percurso educacional que legitime seus diferentes atores e pense a diversidade desde a Educação infantil.

Assim pensar a diversidade implica em pensar a pluralidade e a multiplicidade como condições humanas primárias. "Há que se considerar também que ocorre uma dialética reflexiva entre o singular e o múltiplo no estabelecimento das diferenças e similaridades entre pessoas, grupos e culturas distintas. (FRANÇA, 2010, p.43).

\section{O papel dos Jogos, brincadeiras brinquedos no contexto da diversidade}

Definir jogo, brinquedo e brincadeira têm sido uma tarefa difícil, pois no Brasil, assim como em diversos países, os vocábulos (sobretudo 'jogo'), acabam se tornando imprecisos, por serem empregados com significados diferentes. A escolha do termo adquire significado diferenciado também de acordo com o contexto em que é utilizado.

Esta diversidade de significados resulta não apenas das limitações linguísticas e semânticas, visto que cada língua escolhe uma determinada palavra e determinada ideia na tentativa de expressar sua noção de jogo, brinquedo e brincadeira, como também, dos significados históricos e culturais, próprios do contexto de cada época e de cada povo.

Kishimoto (1997) ressalta que esta dificuldade de definição se apresenta até mesmo em um único termo:

Quando se pronuncia a palavra jogo cada um pode entendê-la de modo diferente. Pode-se estar falando de jogos políticos, de adultos, crianças, animais ou amarelinha, xadrez, adivinhas, contar estórias, brincar de 'mamãe e filhinha', futebol, dominó, quebra-cabeça, construir barquinho, brincar na areia e uma infinidade de outros. Tais jogos, embora recebam a mesma denominação, têm suas especificidades [...]. (KISHIMOTO, 1997, p.13).

A autora destaca a dificuldade linguística, revelando a necessidade de associar a reflexão sobre o jogo à reflexão sobre a lógica da linguagem, na tentativa de entender melhor as concepções presentes. 
Brougère (1998a) aponta que existem vários termos, em português, para denominar aquilo que, em francês, está associado ao vocábulo jeu (sinônimo de jogo). Na língua francesa, por exemplo, jouer significa tanto brincar, recrear quanto jogar ou representar. $\mathrm{O}$ mesmo ocorre com o verbo em inglês to play que significa tanto jogar, brincar, como tocar e representar.

A amplitude terminológica existente nesses idiomas não é possível na língua portuguesa, o que nos leva, frequentemente, a escolher um ou outro termo específico, para representar nossa ideia.

Para Brougère (1998a), cada contexto social cria sua concepção de jogo, não se tratando apenas da ação de nomear, pois o emprego de um termo não é um ato solitário, uma vez que subentende um grupo social para o qual este vocábulo faz sentido. Portanto, a questão é mais cultural do que linguística, pois a língua é apenas um aspecto da cultura.

Toda denominação supõe um quadro sociocultural prévio transmitido pela linguagem e aplicado ao real. [...] Há jogo a partir do momento em que a criança aprende a designar algo como jogo; ela não chega a isso sozinha. Ter consciência de jogar resulta de uma aprendizagem linguística advinda dos contatos da criança desde as primeiras semanas de sua existência. Por detrás da linguagem, é sempre o quadro sóciocultural que aparece. Não há fatos puros de linguagem. (BROUGÈRE, 1998 a, p.18).

Brougère (1998b) afirma em nota de rodapé de seu livro que, na nossa língua (portanto na nossa cultura), o termo brincadeira refere-se preferencialmente a atividades infantis, enquanto que jogo está associado a atividades com regras.

Para Kishimoto (1997) o brinquedo é representado como um objeto suporte da brincadeira, ou seja, brinquedo aqui estará concebido por objetos como piões, bonecas, carrinhos, etc.

Kishimoto (1998) destaca, também, que uma determinada conduta pode ser considerada "jogo" em uma cultura e "não-jogo" em outra. Segundo a autora, trata-se de dar significados diferentes para um mesmo comportamento, utilizando, como exemplo, o atirar com arco e flecha que, dentro da cultura indígena, é uma forma de preparar as crianças para a arte da caça, mas que pode ser entendido por um observador de outra cultura, como uma brincadeira infantil.

Além do fator linguístico e dos contextos históricos, próprios de povos e épocas distintas, outro fator que dificulta (e até impossibilita) uma delimitação exata e única da noção de jogo diz respeito às divergências teóricas sobre o mesmo. 
Tomando essa discussão, Kishimoto (1998) cita que o jogo foi estudado por historiadores (Huizinga, Caillois, Ariès, Margolin, Manson, Jolibert), filósofos (Aristóteles, Platão, Schiller, Dewey), lingüistas (Cazden, Vygotski, Weir), antropólogos (Bateson, Schwartzman, Sutton-Smith, Henriot, Brougère) psicólogos (Bruner, Jolly e Sylva, Fein, Freud, Piaget) e educadores (Chateau, Vial, Alain). Cada estudo desses, em consonância com sua própria natureza, apresenta uma perspectiva de análise de jogo, resultando em abordagens teóricas diferenciadas ${ }^{2}$.

Diante dessas divergências, porém, torna-se importante explicitar que este estudo concebe o jogo, assim como o brinquedo e a brincadeira como fenômenos sociais, atividades culturais. “[...] não é uma dinâmica interna do indivíduo, mas uma atividade dotada de uma significação social precisa que, como outras, necessita de aprendizagem.” (BROUGÈRE, 1998b, p. 20).

O referido autor aponta e critica o que chama de "psicologização contemporânea do brincar”, concepção que prioriza os mecanismos psicológicos, sem levar em conta as influências do mundo, sua dimensão social.

Segundo Brougère (1998b), o jogo, o brinquedo e a brincadeira pressupõem o contexto social e cultural, uma aprendizagem social que permite ao sujeito aprendente entender o conjunto de práticas sociais nas quais se insere.

Desde que nascemos estamos imersos neste contexto e sendo impregnados por ele através de relações interindividuais. Assim, a criança é iniciada nesse mundo lúdico "pelas pessoas que se ocupam dela, particularmente sua mãe ou o adulto que por ela é responsável". (BROUGÈRE, 1998b, p.190).

Kishimoto (1993) destaca o papel da contribuição de povos antigos da Grécia e do Oriente, bem como da participação dos portugueses, negros e índios na formação da cultura, especialmente da cultura lúdica.

$\mathrm{O}$ ato de brincar, assim como os jogos e brinquedos, desencadeia um novo tipo de conhecimento, isso por que carregam um valor histórico passado de geração para geração e normalmente transmitidos oralmente. Uma mesma brincadeira pode receber diferentes regras e/ou nomenclaturas em diferentes culturas e regiões.

O brinquedo é um elemento central nesse contexto, participando da construção da infância através de complexos significados e práticas produzidas não apenas por seus criadores e difusores, como também por aqueles que o utilizam.

\footnotetext{
${ }^{2}$ Essas abordagens não serão apresentadas neste trabalho, mas poderão ser encontradas, por exemplo, em Kishimoto (1997, 1998a) e Brougère (1998a).
} 
É possível entender o lugar da criança na sociedade através dos usos e significados atribuídos aos brinquedos, pois, são portadores de significados e valores culturais que revelam os discursos, concepções e representações da sociedade, revelam os conceitos de infância construídos historicamente pelas culturas.

O brinquedo participa dessa construção da infância e dele é, ao mesmo tempo, consequência, reflexo e uma das causas. O lugar do brinquedo, sua própria existência, a forma que lhe damos, o modo como entra em relação com a criança, depende do lugar da criança na sociedade e das imagens que dela fazemos. (BROUGÈRE, 2004, p. 14).

Para Atzingen (2001) as crianças fazem uso do brinquedo como instrumento de apropriação social e se relacionam com o mundo adulto pelo brincar. A autora aponta o mundo dos brinquedos como um universo mágico, com papel que para além do entretenimento, permite um processo cultural que forma, amplia e institui valores.

Segundo Atzingen (2001) os brinquedos estiveram presentes em todas as civilizações do passado e, ao abordarmos a origem do brinquedo na história é possível comprovarmos sua relevância social e histórica.

Os estudos de Altman (2004) corroboram tal fato, apresentando que as crianças, desde tempos remotos, utilizavam os objetos da natureza, como pedras, folhas, terra e outros como forma de enriquecimento à imaginação. Para a autora, a imitação dos movimentos dos animais, as danças (muito frequentes nas culturas indígenas) também se pautam na natureza.

Em consonância aos pressupostos de Altman (2004) percebemos que ao longo da história as crianças fabricaram seus próprios brinquedos, transformando elementos e objetos e utilizando os materiais que tinham à sua disposição, como pedaços de madeira, espigas de milho, palha e outros. Tal prática pode ser observada e estimulada também na atualidade.

As bonecas, por exemplo, ${ }^{3}$ fazem parte das diferentes culturas desde a antiguidade, conjeturando as relações culturais, políticas e econômicas instituídas nas sociedades e remetendo a diferentes formas de organização da vida das crianças e, sobretudo promovendo o desenvolvimento de sua identidade.

É um dos brinquedos mais populares e antigos do mundo todo. Os bonecos e bonecas reportam as formas humanas (femininas, masculinas e infantis) e podem ser confeccionados com diferentes materiais, acompanhando a evolução dos mesmos e as novas tecnologias.

\footnotetext{
${ }^{3}$ Termo advindo do espanhol 'muñeca'.
} 
Segundo Atzingen (2001) os primeiros bonecos encontrados foram produzidos a cerca de 40.000 mil anos pelo homo sapiens. Usualmente esses bonecos eram esculpidos em pedra e que esses primeiros bonecos não eram usados originalmente para brincar, mas sim, para rituais religiosos, manuseadas pelos sacerdotes e curandeiros. Como exemplo cita os bonecos cognominados Vênus, em referência à deusa grega da fertilidade, pois, preparavam as mulheres para a gravidez.

Os bonecos egípcios eram denominados 'ushtbs' e confeccionados em terracota (argila modelada e depois cozida no forno). Medindo entre 10 e 23 centímetros, tais bonecos eram muitas vezes usados em rituais e colocados nos túmulos para acompanhar os mortos em sua passagem para o outro mundo. "Em túmulos egípcios foram encontradas, ao lado de crianças, bonecas esculpidas em pedaços de madeira com cabelo feito de cordões de argila ou de contas de madeira." (ATZINGEN, 2001, p.29).

Atzingen (2001) afirma que os gregos também utilizavam as bonecas como oferta para as deusas na época do casamento, com a esperança de gerarem filhos. Afirma ainda que o hábito de brincar de boneca pode ter sido derivado dessas figuras religiosas relacionadas com a fertilidade humana.

Conforme a autora, os romanos, utilizavam bonecos e bonecas para homenagear e presentear os deuses. $\mathrm{O}$ uso dos bonecos destinados para o brincar, ou seja, com a função de brinquedo, teve início na Grécia, sendo utilizados de forma recreativa por adultos e crianças, representando heróis e pessoas.

Diferentes estudiosos do brincar (entre eles BROUGÈRE, 2004; KISHIMOTO, 1998; BUJES, 2002, SOUZA, 2009 entre outros) apontam que historicamente as bonecas fazem parte das brincadeiras infantis e representam o conceito que a sociedade tem da infância e de até de si mesma.

Kishimoto (1998) revela em seus estudos que o significado atribuído às bonecas também variam de acordo com as diferenças culturais, pois, "a boneca é brinquedo para a criança que brinca de "filhinha", mas para certas tribos indígenas, conforme pesquisas etnográficas é símbolo de divindade, objeto de adoração. (KISHIMOTO, 1998, p.15).

Podemos citar aqui as bonecas Ritxoko ${ }^{4}$ do povo indígena Karajá que segundo os estudos de Filho e Silva (2012) integram o Patrimônio Cultural Imaterial do Brasil e ilustram uma das várias formas das quais os Karajá exercitam a arte do grafismo. Trata-se de bonecas que são modeladas, pintadas e comercializadas pelas mulheres do povo Karajá.

\footnotetext{
${ }^{4} \mathrm{O}$ termo Ritxoko vem do dialeto feminino Iny e significa 'boneca de cerâmica'. 
Outro exemplo de significância cultural são as bonecas 'Abayomis', de origem africana. As Abayomis (denominação comum na África do Sul) eram confeccionadas pelos negros e ofertadas às crianças como amuleto de proteção, ou como pedido de saúde e Prosperidade ${ }^{5}$.

Advindas da cultura Japonesa, temos as bonecas Ningyoo que refletem claramente toda a evolução histórica do país ${ }^{6}$, assumindo características e funções diferentes em cada período histórico, servindo como ornamentação, diversão, religiosidade, ou até para afastar demônios ou simbolizar força e bravura.

Pode ser lembrada aqui também a boneca Matrioska, conhecida entre nós como boneca Russa (mesmo não sendo comprovada tal origem, que parece na verdade remeter às bonecas japonesas conhecidas como kokeshi e que representam crianças falecidas, feitas com a ideia de preservar e cuidar seus espíritos). As Matrioskas são pequenas bonecas encaixadas umas dentro das outras, talhadas em madeira e pintadas com motivos camponeses e cores vibrantes, que são o reconhecidas como símbolo da personalidade e projeção da alma no espaço. Possuem forma arredondada, simples e acolhedora, e por elas é contada a história da maternidade, do amor. Seu nome procede de Matriona, um nome próprio clássico russo muito comum no final do século XIX no qual se identificam as mães em geral e as matronas. Algumas matrioskas, no entanto, são conhecidas como "Babuskas", que quer dizer avozinha.

Apesar de tantas riquezas e particularidades culturais como essas que foram citadas o que este trabalho gostaria de frisar sobre a realidade dos espaços escolares brasileiros é a constância linear e empobrecida dos brinquedos, especialmente das bonecas e bonecos que são oferecidos às crianças na maioria das escolas. "Pele branca, cabelos loiros, olhos claros, corpo magro e atlético são as formas vigentes dos bonecos e bonecas industrializados que são oferecidos pelo comércio atualmente.” (DORNELLES, 2003, p.4).

\footnotetext{
${ }^{5}$ A palavra abayomi tem origem incerta, iorubá, significando aquele que traz, felicidade ou alegria. Abayomi quer dizer encontro precioso: abay=encontro e omi=precioso. Bonecas artesanais, confeccionadas a partir de sobras de pano reaproveitadas, feitas apenas com nós, sem o uso de cola ou costura e com mínimo uso de ferramentas, sempre negras, possibilitam o trabalho com a identidade afro-brasileira de negros e descendentes, buscando superar as desigualdades de gênero, integrando a memória cultural brasileira. Conta-nos a história Africana que os negros confeccionavam Abayomis como amuleto de proteção. Em viagens para o Brasil em direção à escravidão, as mulheres rasgavam a barra da saia e faziam Abayomis para as crianças brincarem e já aqui como escravos, reunião-se todos os dias na senzala e confeccionavam as Abayomis pedindo saúde e Prosperidade.

(fonte:

http://www.ebc.com.br/infantil/voce-sabia/2012/11/voce-sabe-o-que-sao-abayomis)

${ }^{6}$ Os primeiros bonecos japoneses foram os Haniwa, estatuetas de barro encontradas em tumbas pré-históricas. (fonte: http://pt.wikipedia.org/wiki/Boneca).
} 
Em meus estudos, pesquisas e andanças pelo país ofertando cursos e palestras desenvolvidos para aos professores (as) e professores (as) em formação ${ }^{7}$, comprovo a afirmação de Dornelles (2003) de que a grande maioria das bonecas e bonecos que são dispostas em brinquedotecas e/ou espaços destinados ao lúdico, não permite que se estabeleça uma relação com as diferenças físicas, étnicas ou de gênero.

\begin{abstract}
Algumas materialidades se sobrepõem a outras, produzindo certas 'normalidades', desse modo, é 'natural', no caso do uso de bonecos e bonecas, que os mesmos ao fazerem parte da sala de aula de crianças pequenas sejam da raça branca, com olhos azuis e longos cabelos loiros... Assim, tudo o que escapa ou se apresenta diferente deste 'modelo de normalidade', desta 'verdade' acerca da raça branca, é o 'diferente', o 'outro'. E este é o tipo de brinquedo consumido em série para crianças no que tange às 'diferenças' sejam elas raciais, de gênero, geração ou etnia. (DORNELLES, 2003, p.4).
\end{abstract}

\title{
PARTILHANDO ALGUMAS CONCLUSÕES...
}

Não podemos ignorar a diversidade no contexto escolar e a escola tem um importante papel a cumprir na desconstrução dos estereótipos culturais criados pela sociedade.

O compreender a diversidade e o respeitar as identidades no interior das instituições escolares perpassam o entendimento de que o ensinar e o aprender vão além dos conteúdos, da avaliação e das práticas disciplinares.

A escola deve ser entendida como um espaço onde se valorize a cultura dos 'outros', que se diferenciam do hegemônico cultural. Os alunos são seres individuais que pertencem a diferentes culturas.

A primeira atitude a ser tomada pela escola e pelos educadores é a de compreender os alunos como seres individuais que pertencem a culturas coletivas. Ou seja, um aluno não é igual ao outro. Nem mesmo aqueles que se parecem iguais. A segunda atitude, é compreender esta individualidade como parte de uma coletividade, de um grupo cultural, racial, étnico, econômico, regional, etc. (ROMÃO, 2001, p.10).

É preciso compreender que também os professores (as) são sujeitos culturais, carregam histórias, valores, possuem uma identidade. Seus valores, sua maneira de ver e de relacionar-se com o mundo interfere no seu fazer pedagógico e no seu olhar para com o outro.

\footnotetext{
${ }^{7}$ A título de ilustração dessa afirmação cito o Estado de Mato Grosso, onde há um alto índice de população indígena presente nas escolas públicas, mas que muitos educadores revelaram em cursos de Formação a pouca ou nenhuma existência de bonecas indígenas nas escolas.
} 
Acredita-se aqui que o professor que se compromete com um processo educativo centrado na ludicidade e no respeito às diferenças étnicas, deve preocupar-se em primeiramente:

Problematizar os brinquedos oferecidos para as crianças para que os bonecos e bonecas representem as diferenças e a diversidade cultural. O enfoque dado à dimensão cultural do brinquedo e da boneca como "espelho da sociedade" (BROUGËRE, 2004, p.16).

Pensar em uma educação intercultural na escola é pensar que cabe às escolas e ao professor, enriquecer o repertório lúdico das crianças ofertando bonecas e bonecos distintos que representem a diversidade fenotípica e os diferentes modos de ser sujeito na contemporaneidade.

Outra ação esperada é o processo reflexivo sobre a origem das brincadeiras, jogos e brinquedos que são oferecidos às crianças, uma vez que os mesmos possuem várias origens, integram o folclore brasileiro e marcam os períodos por aqui vividos.

Acolher o brincar infantil como diferentes modos de ser e estar no mundo é uma forma de problematizar a temática da diversidade, descortinando novas expectativas paradigmáticas

Mesmo sem a pretensão de indicar um caminho único a ser trilhado, entende-se que as ideias proporcionadas neste estudo sobre a valorização do brincar, sobretudo no espaço e no processo educativo, constituem uma contribuição no sentido de compreender a multiplicidade cultural e o respeito ao universo lúdico infantil.

\author{
As bonecas \\ sempre alimentadas \\ de banho tomado, \\ dormiam... \\ E eu assim levada, \\ menina peralta, \\ corria o mundo a brincar...
}

(Rita Reikki)

\section{REFERÊNCIAS}

ALTMAN, R. Z. Brincando na história. In: DEL PRIORE, Mary. História das crianças no Brasil. São Paulo: Contexto, 2004, p. 231-258.

ATZINGEN, Maria Cristina Von. A história dos brinquedos - para as crianças conhecerem e adultos se lembrarem. São Paulo: Alegro, 2001. 
ARROYO, M. G.. A pedagogia multirracial popular e o sistema escolar. In: GOMES, N. L. (org.). Um olhar além das fronteiras: educação e relações sociais. Belo Horizonte: Autêntica, 2007, p. 111.

BARBOSA, A. M. Arte cultura e educação. Disponível em: http://dc.itamaraty.gov.br/imagens-e-textos/revista7-mat5.pdf. Acessado em 01/07/2010, 11:00h

BRASIL. Lei 11.645/08, de março de 2008 .

BROUGÈRE, G. Jogo e educação. Porto Alegre: Artes Médicas, 1998a.

. A criança e a cultura lúdica. In: KISHIMOTO, T. M. (Org.). O brincar e suas teorias. São Paulo: Pioneira, 1998b. p.19-32.

. Brinquedo e cultura. São Paulo: Cortez, 2001.

Brinquedos e Companhia. São Paulo: Cortez, 2004.

BUJES, M. I. Infâncias e Maquinarias. Rio de Janeiro: DP\&A, 2002.

Carneiro, M. A. B. A Descoberta do Brincar. São Paulo: Melhoramentos, 2012.

DORNELLES, L. V. Infâncias que nos escapam: da criança na rua à criança cyber. Petrópolis: Vozes, 2003.

FARIA FILHO, L. M. de; VIDAL, D. G. Os tempos e os espaços escolares no processo de institucionalização da escola primária no Brasil. Revista Brasileira de Educação, Campinas, SP, n. 14, p. 20-34, maio/jun./jul./ago. 2000.

FRANÇA, C. de C.. O outro e eu: que relação é esta na educação? IN: O eu e o outro na escola: contribuições para incluir a história e a cultura dos povos indígenas na escola. (Org.) BELENE, Saléte Grando e PASSOS, Luiz Augusto. Cuiabá: EdUFMT, 2010. 168 p.

KISHIMOTO, T. M. Jogo, brinquedo brincadeira e a educação. São Paulo: Cortez, 1997.

O jogo e a educação infantil. São Paulo: Pioneira, 1998.

MARCELLINO, Nelson Carvalho. Estudos do lazer: uma introdução. 2.ed. Campinas: Autores Associados, 2000. (Coleção educação física e esportes).

MASCIOLI, S. Z. Brincar: um direito da Infância e uma responsabilidade da escola. In: Angotti, Maristela (org.). Educação Infantil: para que, para quem e por quê? Campinas, SP: Alínea, 2006.p.105- 116.

As brincadeiras de roda: vamos todos cirandar... In: ANGOTTI, M. (Org.). Educação infantil: da condição de direito à condição de qualidade no atendimento. Campinas: Alínea, 2009. 
As brincadeiras Cantadas: Ressignificando o espaço escolar. In: Angotti, Maristela (org.). Educação Infantil em Diálogos. Campinas, SP: Alínea, 2012. p. 105-120.

NUNES, C. Economia, educação e sociedade: matrizes políticas e estigmas culturais da administração escolar no Brasil. Revista HISTEDBR On-line, Campinas, n. especial, p. 3653, ago. 2006 - ISSN: 1676-25842006. Disponível em: http://www.histedbr.fae.unicamp.br/revista/edicoes/22/art6_22e.pdf. Acessado em: 10/04/2010, 13:00 h.

ROMÃ̃, J. Por uma educação que promova a AutoEstima da Criança Negra. Brasília: Ministério da Justiça,Secretaria de Estado dos Direitos Humanos, 2001.

SANTOMÉ, J. T. Culturas Negadas e Silenciadas no Currículo. In: SILVA, T. T. Alienígenas na Sala de Aula: Uma Introdução aos estudos culturais em educação. Petrópolis: Vozes, 2009.

SARMENTO, M. J. As culturas da infância nas encruzilhadas da $2^{\text {a }}$. Modernidade. Braga. Centro de Estudos da Criança da Universidade do Minho, 1997.

SARAIVA, João Batista da Costa. Direito penal juvenil: adolescente e ato infracional. Garantias processuais e medidas socioeducativas. $2^{\mathrm{a}} \mathrm{Ed}$, Porto Alegre. Livraria do Advogado. 2002.

SOUZA, F. M. Revirando Malas: entre histórias de bonecas e crianças. Dissertação (Mestrado em Educação) - Programa de Pós-Graduação em Educação, Faculdade de Educação, Universidade Federal do Rio Grande do Sul, Port o Alegre, 2009.

FILHO, M. F. L. e SILVA, T. C. da. A arte de saber fazer grafismo nas bonecas Karajá. Horiz. antropol. vol.18 no.38 Porto Alegre July/Dec. 2012. Disponível em: http://www.scielo.br/scielo.php?pid=S0104-71832012000200003\&script=sci_arttext Acesso: 18-08-2015 